Review

\title{
Current treatment of breast cancer in the United States
}

\author{
Roy Ashikari and Patrick L. Mo't \\ Department of Surgical Oncology \\ New York Medical College Westchester Medical Center \\ Valhalla, New York 10595, USA
}

(Received for publication on July 24, 1986)

\begin{abstract}
Breast cancer is one of the most common malignancies among women in the United States. Based on 1,150 cases operated by the author, $56 \%$ of all operable breast cancers were treated either by radical mastectomy or extended mastectomy and $44 \%$ were treated by modified mastectomy during the 5 year period from 1974-1978. However, in $1985,20 \%$ of the patients were treated by partial mastectomy and radical mastectomy was performed on only $5 \%$ and the rest were treated by modified radical mastectomy. These changes in the treatment of breast cancer are now being seen throughout the United States.

Adjuvant chemotherapy treatment has been routinely given patients in the United States who have metastases to the regional lymph nodes for the past 10 years. Currently, CMF or CMFVP combinations of chemotherapy are the most commanly used for 9 or 12 month's duration. Some institutions use anti-estrogen (tamoxifen) as adjuvant treatment for the patient who has an estrogen receptor positive tumor. Conservative treatment of breast cancer will probably increase to $25-30 \%$ of primary breast cancers in the near future in the United States, but treatment should be determined individually.
\end{abstract}

Key words: breast cancer, mastectomy, adjuvant chemotherapy, anti-estrogen

Roy Ashikari, M.D. is Chief of Surgical Oncology and Professor of Surgery, New York Medical College, Consultant Breast Service, Memorial Sloan-Kettering Cancer Center, New York, Professor, Tokai University School of Medicine, Kanagawa Pref., and Professor, School of Medicine. Keio University, Tokyo.

Patrick L. Molt, M.D. is Assistant Professor of Surgery, New York Medical College. 
Breast cancer is one of the most common malignancies among women in the United States. Estimated incidence of breast cancer in 1986 in the United States will be 123,000 cases detected and 40,200 deaths this year. Despite advances in diagnosis and treatment in recent years, the death rate from this disease has not changed from 50 years ago. Breast cancer is characterized by multicentric origin in most cases and not only increases in size at the primary site, but often metastasizes to regional lymph nodes. For this reason, all stages of potentially curable breast cancer have been treated with Halsted type radical mastectomy for many years. This involves complete removal of all breast tissue including underlying pectoral muscle in continuity with removal of regional lymph nodes. During the past ten years, however, this radical surgical treatment has changed to modified mastectomy. Recently, treatment has begun to include not only modified mastectomy but also partial mastectomy with radiation therapy. Current surgical treatment of breast cancer is as follows:

Local Treatment:

1. Radical mastectomy

2. Modified radical mastectomy

3. Partial mastectomy with lymph node dissection and radiation therapy

4. Lumpectomy with interstitial implant followed by external radiation.

Adjuvant Systemic Treatment:

1. Cytotoxic chemotherapy for node positive premenopausal women

2. Anti-estrogen (tamoxifen) for node positive hormone receptor positive postmenopausal patients.

In my experience at Memorial S!oan-Kettering Cancer Center in New York, $77 \%$ of all operable breast cancer were treated by radical mastectomy, and only $14 \%$ were treated by modified mastectomy in 1969. Ten years later, in 1978, 52\% of patients with breast cancer were treated by modified mastectomy and in 1985, modified mastectomy was performed in $71 \%$ of all breast cancer and only $3 \%$ were treated by radical mastectomy. Furthermore, at present, $20 \%$ of the patients with breast cancer have been treated by partial mastectomy, axillary node dissection followed by radiation therapy (Table 1).

From my own experience, based on 1,150 cases, $56 \%$ of all operable breast cancers were treated either by radical mastectomy or extended mastectomy and $44 \%$ were treated by modified mastectomy during the 5 year period from 1974-1978. However, in $1985,20 \%$ of the patients treated by partial mastectomy and radical mastectomy was performed on only $5 \%$ and the rest were treated by modified radical mastectomy (Table 2). These changes in the treatment of breast cancer are now being seen throughout the United States. According to a study done by the American College of Surgeons 
Table 1

Experience at Memorial Sloan-Kettering Cancer Center, 1985

\begin{tabular}{lrr}
\hline Partial mastectomy, axillary dissection, R.T. & 154 & $20 \%$ \\
Modified mastectomy & 524 & $71 \%$ \\
Radical mastectomy & 26 & $3 \%$ \\
Extended radical mastectomy & 2 & \\
Total mastectomy & 29 & $3 \%$ \\
& Total & 735 \\
\hline
\end{tabular}

Table 2

Personal experience, type of surgery, 1969-1985

\begin{tabular}{|c|c|c|c|c|c|}
\hline & Radical & Modified & Partial & $\begin{array}{c}\text { Extended } \\
\text { Radical }\end{array}$ & Simple \\
\hline $\begin{array}{l}1968 \text { to } 1973 \\
188 \text { Cases }\end{array}$ & $\begin{array}{c}144 \\
(76 \%)\end{array}$ & $\begin{array}{c}25 \\
(13 \%)\end{array}$ & & $\begin{array}{c}18 \\
(9 \%)\end{array}$ & \\
\hline $\begin{array}{l}1974 \text { to } 1979 \\
520 \text { Cases }\end{array}$ & $\begin{array}{c}249 \\
(47 \%)\end{array}$ & $\begin{array}{l}246 \\
(47 \%)\end{array}$ & 1 & $\begin{array}{c}22 \\
(4 \%)\end{array}$ & 2 \\
\hline $\begin{array}{l}1980 \text { to } 1985 \\
411 \text { Cases }\end{array}$ & $\begin{array}{c}33 \\
(8 \%)\end{array}$ & $\begin{array}{c}331 \\
(80 \%)\end{array}$ & $\begin{array}{c}42 \\
(10 \%)\end{array}$ & 3 & 3 \\
\hline $\begin{array}{l}\text { Total } \\
1119 \text { Cases }\end{array}$ & $\begin{array}{c}426 \\
(38 \%)\end{array}$ & $\begin{array}{l}602 \\
(54 \%)\end{array}$ & $\begin{array}{l}43 \\
(4 \%)\end{array}$ & $\begin{array}{c}43 \\
(4 \%)\end{array}$ & 5 \\
\hline
\end{tabular}

Unilateral Breast Cancer 1968-1985.

Commission on Cancer reported in 1982,1 $90 \%$ of breast cancer patients were treated by modified mastectomy in 1981 , but cancer patients were treated by modified mastectomy in 1981, but recently partial mastectomy followed by radiation accounts for about 10-15\% of the treatment for breast cancer in the United States.

A modified mastectomy is the most commonly used procedure for the treatment of breast cancer today. In accordance with the recommendation made by the Consensus Conference on the Treatment of Breast Cancer held at the National Institute of Health in 1979, modified mastectomy is the most satisfactory a.ternative treatment to Halsted radical mastectomy for Stage I breast cancer.? Modified mastectomy should be the total removal of the breast with adequate lymph node dissection (Fig. 1). Adequate axillary node dissection can be accomplished with (Patey type) or without (Auchincloss type) the removal of the pectoralis major muscle. ${ }^{3}$ The choice of using either procedure depends upon the individual surgeon. If breast reconstruction is being considered for the future, preservation of both the pectoralis major and minor muscles is cosmetically superior to preserving one muscle alone. 


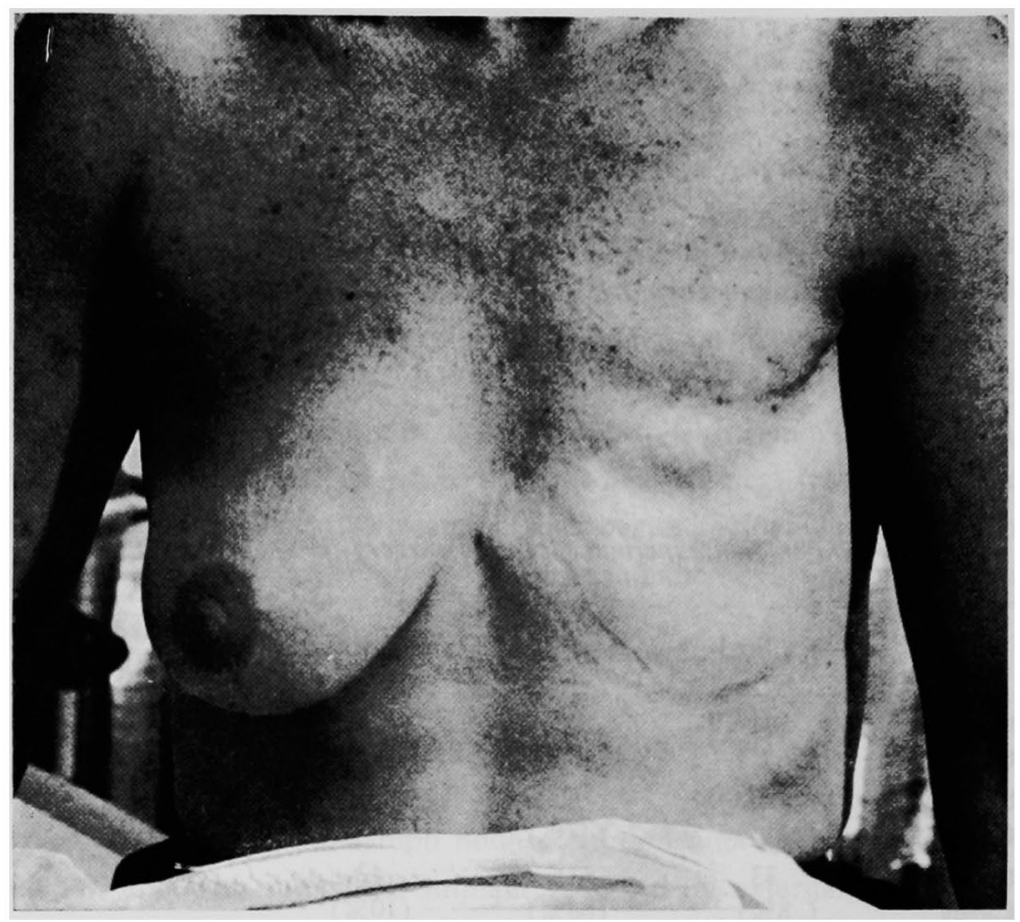

Fig. 1 Appearance after modified mastectomy.

Partial mastectomy with node dissection followed by post-operative radiation has been getting more attention for the past several years in the United States (Fig. 2). Partial mastectomy consists of the removal of breast tissue well around the primary site with in continuity or discontinuous axillary lymph node dissection. External irradiation of 5,000 rads in 5 weeks will be delivered to the breast.

Partial mastectomy without irradiation is also performed on selected favorable patients.

In the case of a lumpectomy, additional radiation therapy using interstitial radioisotope implant ( ${ }^{192}$ Iridium) is given at the site of the primary tumor, either at the time of the lumpectomy or after completion of the external radiation (Fig. 3).

Radical mastectomy accounts for only $5 \%$ of all surgical procedures performed for breast cancer at the present time. It is used mostly for locally advanced tumors, such as a large tumor affixed to the underlying pectoral muscle or obvious tumor involvement in the regional lymph nodes. An extended radical mastectomy has not been used in recent years. If the tumor is located medially or centrally, a biopsy of the internal mammary lymph nodes is performed in some institutions, and if there is node involvement, post-operative radiation is given to these areas. 


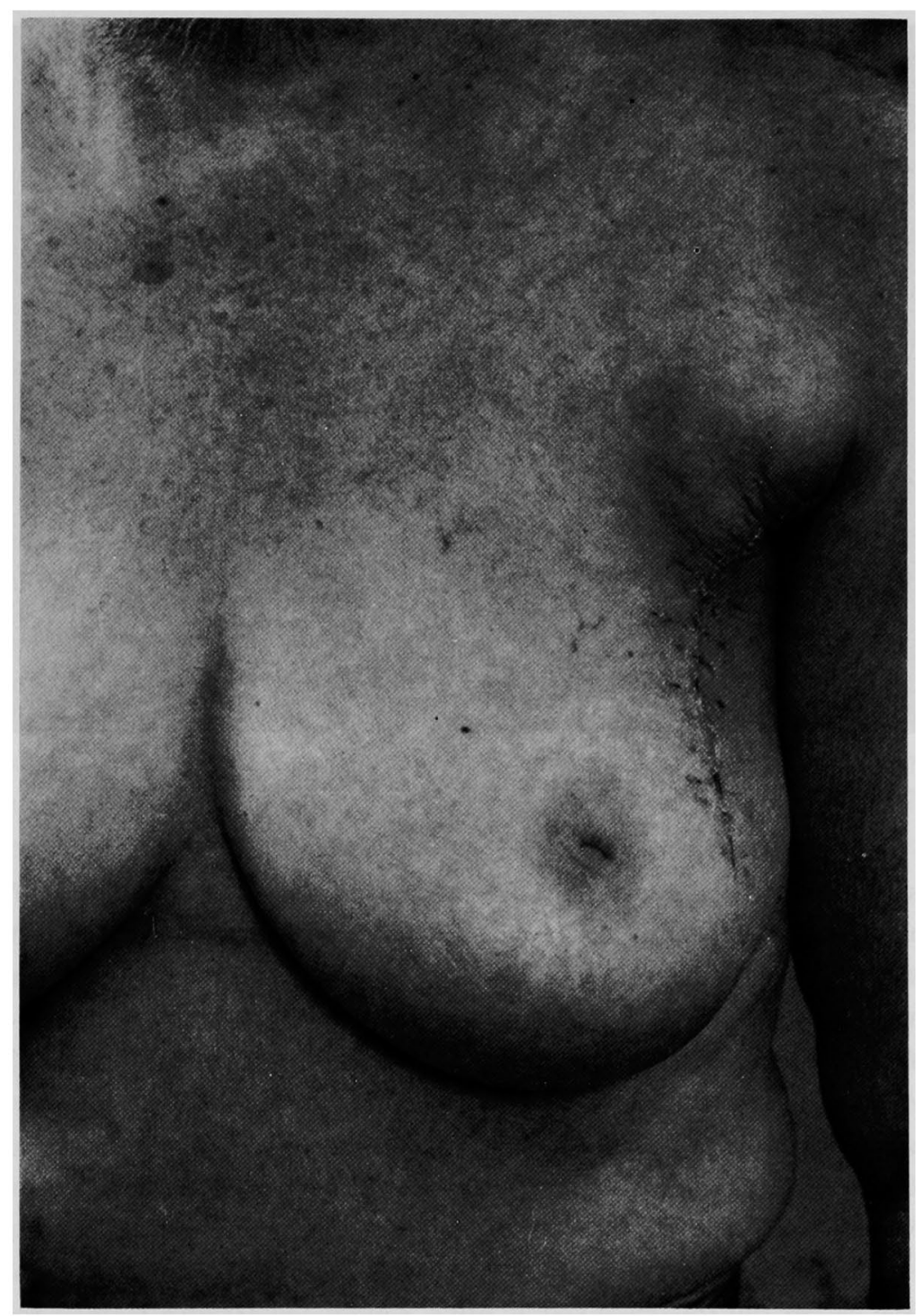

Fig. 2 Appearance after partial mastectomy and lymph node dissection.

Why then has the surgical management of breast cancer become more conservative and less aggressive? The reason for this conservative trend is a changing concept of breast cancer itself. Originally it was thought upon hypothesis that breast cancer remained a local disease confined only to the breast itself or to the breast and its regional lymph nodes until it reached an advanced stage. Therefore, aggressive surgical treat- 


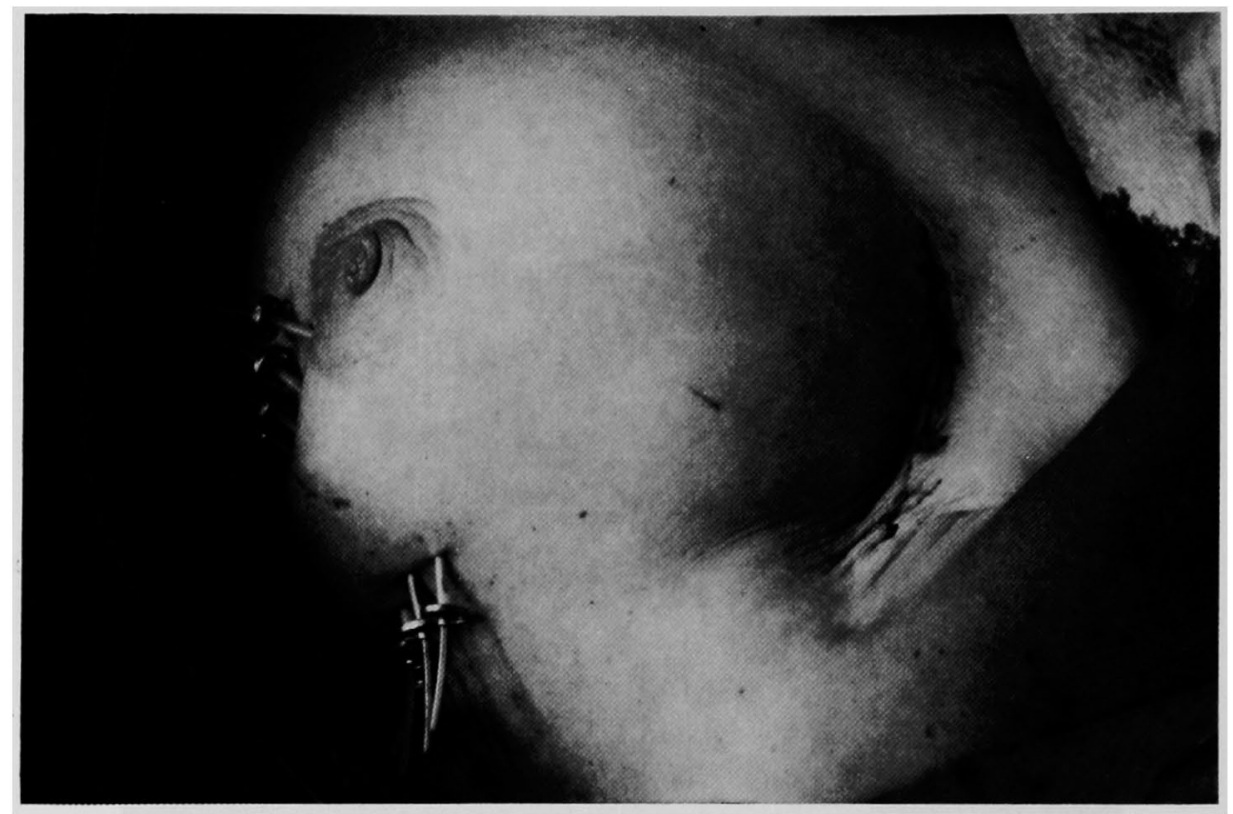

Fig. 3 Lumpectomy with interstitial implant.

ment was necessary to eliminate local disease. Recently, even in the "early" stage of the disease, systemic dissemination has been demonstrated in some instances. Aggressive local treatment does not alter the fate of such patients when compared to less aggressive treatment.

Another question is whether conservative treatment controls local disease adequately. According to the accumulated data of several retrospective and prospective studies, conservative treatment with partial mastectomy and irradiation controls local disease as well as the more aggressive treatment such as mastectomy. The final reason for the trend toward conservative treatment is that it achieves more acceptable cosmetic results and maintains sexuality and femininity with better psycho'ogical effects on the patient. Despite the successfull treatment results using a more conservative method reported by Mastakallio,, Peters, ${ }^{5}$ Atkins \& Hayward, ${ }^{6}$ Prosnitz, ${ }^{7}$ Calle, ${ }^{8}$ Amalric ${ }^{9}$ and Harris, ${ }^{10}$ still has not solved the problem and questions remain.

In reviewing the experience of the Joint Center for Radiation Therapy, Harris ${ }^{10}$ reported local control in Stage I cancer which was $96 \%$ and $84 \%$ in Stage II in 5 years and in the 10 year follow-up, cumulative survival in Stage 1 was $96 \%$ and $68 \%$ in Stage II cancer, which is comparable with more aggressive local treatment. Osborne ${ }^{11}$ reported high local-regional recurrence rate of $22 \%$ in T1T2N1 patient group and $52 \%$ in $\mathrm{T} 2 \mathrm{~N} 1$ group treated by wide excision followed by 4,500 rads using orthovoltage 
technique. Hayward ${ }^{12}$ also reported $30 \%$ local-regional recurrence in the T1T2N0 patient group after treatment of 3,800 rads using $300 \mathrm{KV}$ machine. Furthermore, from a histopathologic standpoint, Connelly ${ }^{13}$ reported local failure after radiation therapy is associated with a prominent intraductal component within the tumor, non-invasive carcinoma in adjacent tissue and poor cytologic differentiation of the primary tumor. Fisher ${ }^{14}$ also indicated that intralymphatic extension by the tumor contributed to a high incidence of local recurrence after radiation therapy. Whatever the results were, these studies, some conducted prospectively on a randomized basis, others prospectively among selected patients and others retrospectively show that no firm conclusion can be made as to which treatment is superior to the other in comparing the types of treatment.

As far as the surgical technique used and its side effects are concerned, there is no difference in the length of surgical time, hospital stay and complications (such as the amount of seroma, wound infection, swelling in the arm) between a modified mastectomy and a partial mastectomy with lymph node dissection. Radiation therapy has certain undesirable side effects. Harris ${ }^{10}$ reported $5 \%$ of irradiated patients had rib fractures, $2 \%$ had radiation pneumonitis and $4 \%$ had arm edema as immediate side effects, besides swelling, edema, telangiectasia and hardening of the skin. As a later side effect, the carcinogenic potential by radiation is a well known phenomenon, but how frequently it occurs is still not clear. Ferguson ${ }^{15}$ reported 4 sarcomas and 2 cancers of the esophagus. Huvos ${ }^{16}$ reported 6 sarcomas out of 66 "radiation induced" sarcomas in association with previous irradiation for breast cancer. Kuten ${ }^{17}$ reported 7 cases of sarcoma after irradiation for breast cancer.

What then is the real benefit and advantage in preserving the breast during treatment of breast cancer? Does the improved sexual and body image and the overall psychological adjustment of patients who are treated with conservative management justify the cost, inconvenience and potential morbidity? Is it worthwhile to go through 5 weeks of radiation therapy especially with inconvenience to elderly patients and the fear of future recurrence and carcinogenic effects among young patients? Does partial mastectomy and radiation therapy really maintain superior cosmetic results as compared to the reconstructed breast after a mastectomy in the case of a patient with small breasts or when the primary tumor is located cenrally or in the medial half of the breast? Doesn't the removal of a large tumor mass leave a distorted breast? Montague ${ }^{18}$ reported $14 \%$ of the patients developed severe fibrosis and $22 \%$ developed breast edema after irradiation; even Harris reported that $73 \%$ of the patients so treated by radiation had excellent cosmetic results.

Currently, two prospective randomized studies comparing both modified mastectomy and partail mastectomy followed by radiation therapy are under way in Italy (Veronesi) ${ }^{19}$ and in the U.S.A., NSABP B06 protocol.20) The preliminary reports show significant enthusiasm, but the duration of the follow-up period of these studies is too 
short to make any definitive conclusion at this time. It will take another 6-7 years to get meaningful results from these studies. Until then, the indication for conservative treatment is very limited to small cancers, Stage I, preferably located at the upper outer quadrant of the breast for cosmetic purposes. It is not the treatment of choice at this time for the following groups:

1. Age-younger patient in the 20 's or in the 30 's. Older patient in the 70 's or in the 80's

2. Size - if the size of the tumor is more than $2 \mathrm{~cm}$ in diameter

3. If the size of the breast is extra small or extra large

4. If the location of the tumor is central or medial

5. If the tumor is poorly differentiated

6. If there is non-invasive carcinoma in adjacent tissue

7. If there is any multi-centric origin, either with a separate primary on clinical examination or diffuse tumor type calcification on mammography

8. If there is intra-lymphatic extension

9. During pregnancy.

Partial mastectomy and lymph node dissection without radiation therapy has been reported by Crile21 with a good result in treating early selective breast cancer. Currently, it is under study by NSABP B06 protocol ${ }^{20}$ and the preliminary report indicates a higher rate of local recurrence noted among the group without radiation therapy when compared with the radiated group. There is no difference in survival rates in both groups. Partial mastectomy without radiation has been used in selected cases such as poor medical risk patients, elderly patients and patients with a very isolated small primary tumor. If the tumor is small enough, less than $2 \mathrm{~cm}$ in diameter and located at the upper outer quadrant on the breast, particularly if it is the patient's preference, there is no reason not to do conservative treatment. In my personal series, $43 \%$ of patients presented with tumors $2 \mathrm{~cm}$ or less located other than centrally and thus could be candidates for breast preserving surgery. The number of conservatively treated cases will increase, probably to $25-30 \%$ in the near future in the United States.

Adjuvant chemotherapy treatment has been routinely given patients in the United States who have metastases to the regional lymph nodes for the past 10 years. However, according to the Concensus Development Conference held at the N.C.I. in 1985, adjuvant chemotherapy treatment for breast cancer is not as beneficial as originally thought, except in pre-menopausal women. Currently, CMF or CMFVP combinations of chemotherapy are the most commonly used for 9 or 12 month's duration. Some institutions use anti-estrogen (tamoxifen) as adjuvant treatment for the patient who has an estrogen receptor positive tumor. Hormone receptor studies from cancer tissues are also routine 
procedures. This information is important, not only in determining what kind of treatment is necessary at the time of recurrence, but also used for anti-estrogen as an adjuvant therapy.

Also, as recent trends indicate, a fair number of patients ask for a biopsy of the tumor first and then definative treatment in separate steps-the so-called two stage operation. An advantage of this procedure is that the pathology of the biopsy specimen can be examined more extensively by permanent sections and also the patient has a chance to get a second opinion before deciding what type of procedure should be performed. As a disadvantage, the patient requires two separate anesthesias and it prolongs hospitalization. In order to avoid any misunderstandings and confusion between the patient and the surgeon, the surgeon must explain to the patient, not only the outcome of the procedure, but also what alternative treatments are available for breast cancer treatment.

Reconstruction of the breast after a modified mastectomy is also becoming quite popular over the past 10 years. Most of the reconstruction has been done 5-6 months after the mastectomy. McCann double lumen silicone prosthesis is the one most commonly used. This is placed under the pectoralis major muscle with very acceptable cosmetic results and resultant psychological benefits (Fig. 4).

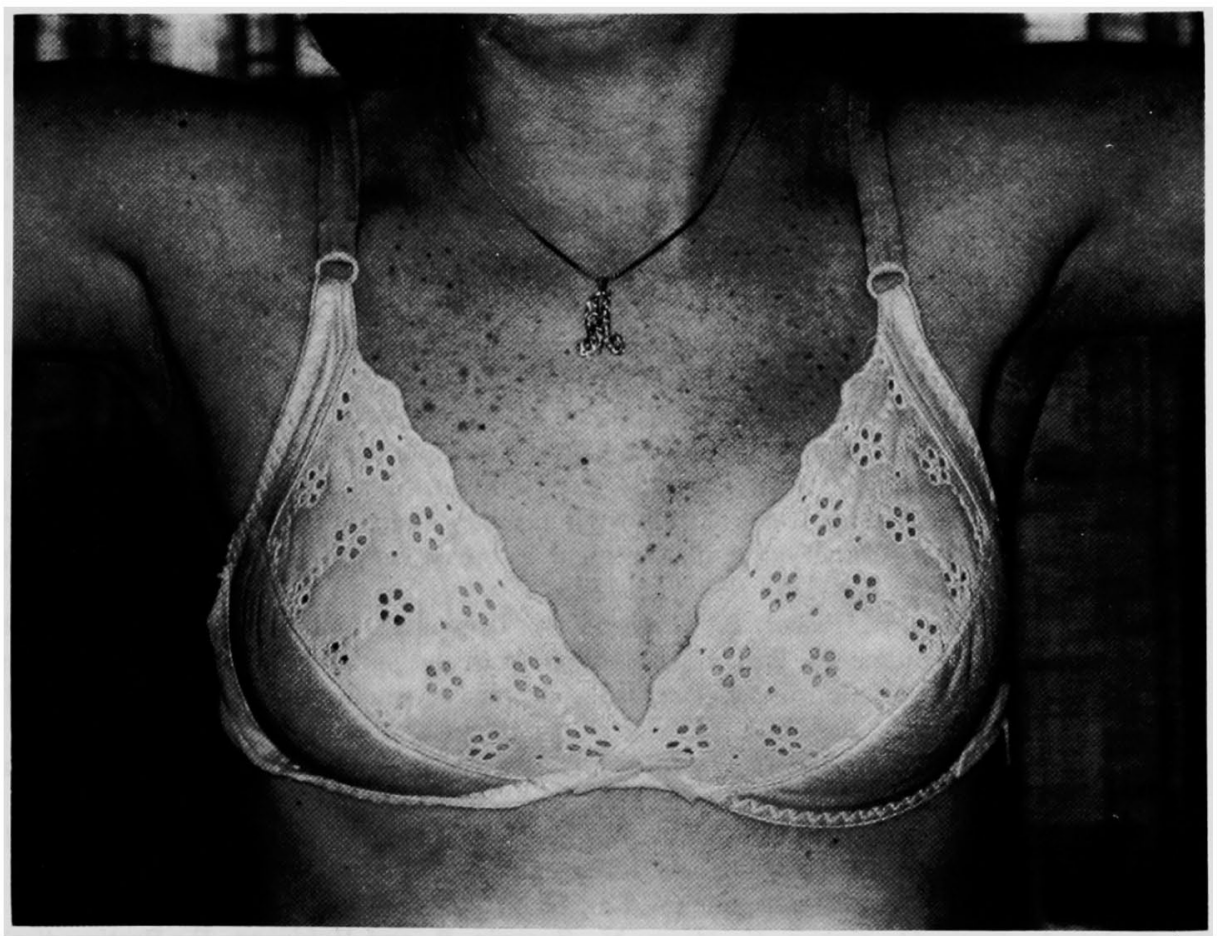

Fig. 4 After reconstruction with brassière on. Same patient as in Fig. 1. 
In summary, conservative treatment of breast cancer will probably increase to 25-30\% of primary breast cancers in the near future in the United States, but treatment should be determined individually, case by case, considering the patient's age, size of the tumor in proportion to the patient's breast, histology and other factors among the surgeon, radiation oncologist, medical oncologist and the patho'ogist.

\section{References}

1. Amercian College of Surgeons Commission on Cancer. "Long term and short term surveys in patterns of care of the female breast in the American college of surgeons approved cancer programs' Report to commission on cancer patients care and research committee," Oct. 22, 1982

2. NIH Consensus Development Program Treatment of Primary Breast Cancer, June 5, 1979

3. Ashikari, R. H.: Modified radical mastectomy. Surg. Clinic of North America 62: 10951102,1984

4. Mastakallio, S.: Conservative treatment of breast carcinoma: Review of 25 years followup. Clin. Radiol. 23: 110-1156, 1972

5. Peters, M. V.: Wedge resection with or without radiation in early breast cancer. Int. J. Radiat. Oncol. Biol. Phys. 2: 1151-1156, 1972

6. Atkins, H. and Hayward, J. L.: Treatment of early cancer. A report after ten years of clinical trial. Br. Med. J. 2: 423-429, 1972

7. Prosnitz, L. R. and Goldenberg, I. S.: Radiation therapy as primary treatment for early stag carcinoma of the breast. Cancer 35: 1587-1596, 1975

8. Calle, R., Pilleron, J. P., Schlienger, P. and Vilcoq, J. P.: Conservative management of operable breast cancer. Ten years experience at the foundation curie. Cancer 42: 20452053, 1978

9. Amalric, R., Santamaria, F., Robert, F., Seigle, J., Altschuler, C., Kurtz, J. M., Spitalier, J. M., Brandon, H., Ayme, Y., Dollet, J. F., Burmeister, R. and Abed, R.: Radiation therapy with or without primary limited surgery for operable breast cancer. Cancer 49: 30-34, 1982

10. Harris, J. R., Beadle, G. H. and Hellman, S.: Clinical studies on the use of radiation therapy as primary treatment of early breast cancer. Cancer 53: 705-711, 1984

11. Osborne, M. P. and Ormiston, N.: Breast conservation in the treatment of early breast cancer. Cancer 53: 349-355, 1984

12. Hayward, J. L.: The Guy's Hospital trials on breast conservation. Conservative Management of Breast Cancer. J.B. Lippincott Company, Philadelphia. 1983, 77-79

13. Connolly, J. L., Schmitt, S. J., Harris, J. R., Hellman, S. and Cohen, R. B.: Pathologic correlates of local tumor control following primary radiation therapy in patients with early breast cancer. Conservative management of breast cancer. J.B. Lippincott Company, Philadelphia. 1983, 123-136

14. Fisher, E. R., Sass, R., Fisher, B., Gregorio, R., Brown, R. and Wickerham, L.: Collaborating Nsabp Investigators. Pathologic findings from the national surgical adjuvant breast project (Prot.-6). Relation of local breast recurrence to multicentricity. Cancer 57: 17171724,1986

15. Ferguson, D. J. and Sutton, H. G.: Late Effects of adjuvant radiotherapy for breast cancer. Cancer 54: 2319-2323, 1984

16. Huvos, A. G., Woodard, H. Q., Cahan, W. G., Higinbotham, N. L., Stewart, F. W., Butler, A. and Bretsky, S. S.: Postradiation osteogenic sarcoma of bone and soft tissue: A clinicopathologic study of 66 patients. Cancer $5 \mathrm{~g}: 1244-1255,1985$

17. Kuten, A., Sapir, D., Cohen, Y., Haim, N., Borovic, R. and Robinson, E.: Postirradiation soft tissue sarcoma occurring in breast cancer patients: Report of seven cases and results 
of combination chemotherapy. J. Surg. Oncology 28: 168-171, 1985

18. Montague, E. D., Schell, S. R., Romsdahl, M. H. and Ames, F. C.: Conservation surgery and irradiation in clinically favorable breast cancer. The M. D. Anderson Experience. Conservative management of breast cancer. J.B. Lippincott Company, Philadelphia. 1983, $53-59$

19. Veronesi, U., Saccozzi, R., Del Vecchio, M., Banfi, A., Clemente, C., De Lena, M., Gallus, G., Greco, M., Luini. A., Marubini, E.. Muscolino, G., Rilke, F., Salvadori, B., Zecchini, A. and Zucali, R.: Comparing radical mastectomy with quadrantectomy axillary dissection and radiotherapy in patients with small cancers of the breast. N.E. J. Med. 305: 6-11, 1981

20. Fisher, B., Bauer, M., Margolese, R., Poisson, R., Pilch, Y., Redmond, C., Fished, E., Wolmark, N., Deutsch, M., Montague, E., Saffer, E., Wickerham, L., Lerner, H., Glass, A., Shibata, H., Deckers, P., Ketcham, A., Oishi, R. and Russell, I.: Five year results of a randomized clinical trial comparing total mastectomy and segmental mastectomy with or without radiation in the treatment of breast cancer. N.E. J. Med. 312: 665-673, 1985

21. Grile, G., Cooperman, A., Esselstyn, C. B., Campos, G. and Liggins, G. C.: Results of partial mastectomy in 173 patients followed from five to ten years. Surg. Gynecol. Obstet. 150: $563-566,1980$ 